\title{
Analysis on Magnificent Form of Hankou's Modern Architecture and Water Mutually Reinforcing and Neutralizing Each Other
}

\author{
Hai Cheng \\ School of Fine Art \\ Huanggang Normal College \\ Huanggang, Hubei, China 438000
}

\begin{abstract}
Hankou prospers due to water, which has always been the power and source of development of Hankou, playing a decisive role in modern architecture of Hankou. Hankou's modern architectural form transferred to magnificent form focusing on high-bench buildings from traditional Chinese buildings due to "water", whose architecture is grand and forceful, and aesthetic connotation and emotional power are strong.
\end{abstract}

\section{Keywords-Hankou; water; architecture; magnificent}

\section{INTRODUCTION}

Hankou prospers due to water, which has always been the power and source of development of Hankou, playing a decisive role in modern architecture of Hankou. The modern architecture of Hankou is the result of architecture and water mutually reinforcing and neutralizing each other. In modern times, water and war repeatedly destroyed old buildings in Hankou, which didn't decline due to natural and man-made disaster but kept developing, and the architectural form developed into modern architecture focusing on high-bench buildings from shack, stilted building and cob-wall bungalow originally built along Han River and Hucha, and developed toward magnificent form. The magnificent form refers to the grand forceful manly beauty of architecture, whose architecture is grand and forceful, and aesthetic connotation and emotional power are strong, and also it is feature of Hankou's modern architecture which prospers due to water.

\section{ARCHITECTURE OF ANCIENT TOWN IN HANKOU WHICH PROSPERS DUE TO WATER}

In ancient times, Han River flowed into Yangtze River, during Cheng Hua period in Ming Dynasty, the main stem of it flowed in to Yangtze Estuary via north of Guishan instead, making Hankou and Hanyang two separate places. "Hide bent continent with water. It can shelter from the wind, the water is shallow, the continent is bent, and it can anchor"'[1], merchant ships along the Yangtze River berthed at the north bank of Han River. Hankou is located at the intersection of Han River and

Project source: funding project of general project of Hubei social science funds (No.2014204); funding project of Edong education and culture research center, key research base of humanities \& social sciences of Hubei regular institutions of higher learning (No .2014003403); research project of experiment teaching of 2014 experiment teaching demonstration center of Huanggang Normal College2014 (No. Zj201413). the Yangtze River, which makes Wuhan a decisive economic hub in the midland. Hankou is a water area integrating river and lake, where continent is formed due to alleviation and sedimentation of sand brought by rivers. Along with artificial filling and polder construction, it developed into downtown, and the change of river, lake and harbor limits the existence and development of Hankou. Hankou "started from middle of Ming Dynasty, prospered in Tian Qi and Chong Zhen periods. [2] During Jia Jing's reign in Ming Dynasty, there were four residences of Juren, Youyi, Xunli and Dazhi. In late Ming and early Qing dynasties, social turmoil had deep influence on development of Hankou, old buildings developed slowly. Hankou became important commercial town during "KangQian Flourishing Age", and traditional Chinese official buildings and residential buildings further developed, which was connected to the recovery and development of social economy in Qing Dynasty. It is said in "Guangyang Note" that "there are four gathers, Beijing in north, Foshan in south, Suzhou in east, Hankou in west. On the coast of the East China Sea, out of Suzhou, and there is also Wuhu, Yangzhou, Jiangning and Hangzhou which separate its power, and there is only Hankou in the west" [3], Hankou is located in the four gathers of the country, which is especially important. During Jiaqing's reign during Qing Dynasty, Hankou was called as "Four famous towns" together with Zhuxian in Henan, Jingde in Jiangxi and Foshan in Guangdong. Hankou almost became the synonym of Wuhan, and Wuhan's status and popularity improved a lot centered on Hankou. Mizuno Yukiyoshi mentioned in "Hankou" that "government offices are mostly bungalows, paved with sand in general room, or with wood spot, or with chairs placed on, and the central equipment desk is always circled to sit around." ever since the 19th century, industrial associations, guild halls, temples and Taoist temples launched public buildings with various styles and grand vigor, which shew magic atmosphere of local features and oriental culture, and the official buildings shew the beautiful form of oriental buildings.

The traditional streets of old downtown of Hankou have developed into quite a scale, according to "journal of Xiakou County", there were 200 guild halls and industrial associations, among which there were over 140 whose construction time could be verified, and 56 ones' construction time was 
unknown. Guild halls in Lingnan, Fujian, Zhejiang, Jiangxi and Baoqing had large scales. Shanshanxi Guild Hall on Hanzheng Street had the larges scale among all, Yilin from Pingyao, Shanxi once wrote that "ever since the country formed, it has always been prosperous, the temples are completing, resplendent and magnificent, among which western guild halls have large scales." "General drawing of Hankou's western guild halls" said that "there are tall walls tier upon tier, deep courtyard, palaces one after another, extending porches and peaceful gardens. Out of the gate there is Sandou iron flagpole as tall as gate tower. Enter the gate and go inside, there are front and back halls, white-stone stairs and corridors, carved beams and painted rafters, golden tile and green eave. There is a large stage behind the front hall and Guandi statue in the back hall, on every festival, there would be performance in the guild hall, on the second floor of the wings on the two sides, rows of carved windows are opened, audience crowd upstairs and downstairs, inside and outside the hall." It was wrote in "Culture of guild halls of Shanxi merchants" that "there are four stages of main hall, Fiscal deficit Temple, Seven Sage Hall and Wenchang Hall in Shanshanxi Guild Hall in Hankou"[4], Shanshaanxi Guild Hall in Hankou had large scales, covering an area of around 5500 sq.m, which was divided into 3 courtyards in the east, middle and west, the courtyards are connected by long and narrow roadways, which were special in Shanxi dwellings, and there were over 10 main buildings inside the guild hall. We can know the status of this hall among buildings at that time from existing pictures and dictation of the old, the whole building has carved beams and painted rafters, charismatic, with pavilions, halls and open halls, which was the most magnificent and beautiful in Wuhan. In 1854, the guild hall was destroyed by war fire, in 1870 , people raised funds to rebuild it. During the Anti-Japanese War, the most of the hall was destroyed by Japanese invaders, and the last building of the guild hall, Chunqiu House was dismantled during the Great Cultural Revolution.

Apart from the guild hall and buildings of industrial associations in the old downtown, there were mostly government offices, dwellings and buildings of some social charitable organizations, all in wood structure, mainly in courtyard distribution. [5] In downtown, there were mainly stores and dwellings, and the houses along the street were low with the first floor as pavement and dwelling upstairs. Most of the gates of stores facing the street can be all taken down, and there was only one gate facing the street, on the two sides of which were windows, and there were counters on the two sides in the store hall. In old times, there were always round nail and iron sheet on the gate of the store, and a bulky beam was between the first and second floor with patterns of dragon and phoenix and painted with red painting. On the coast of Han River, bank of Yangtze River or on the back lake, there were rows of stilted buildings, endowing Hankou with style of watery place. A female missionary wrote in her diary in May. 1885 that "these houses are like the roles with hunchback in English puppet shows, the low part of which were supported by timber piles, and many houses are severely tilted and they always fall down together." We can see from the existing pictures that at that time, the main street of Hankou were paved with quartzite, which were not wide, about $3-7 \mathrm{~m}$, the building forms were natural and fresh with no uniform planning, the buildings facing the street were uneven, mainly in post and panel structure, and a Chinese town of slow life stood vividly revealed on the paper. The stilted buildings near water shew idyllic scenery in watery place, whose architecture form was plain and natural.

\section{REGIONAL MAGNIFICENT ARCHITECTURAL FORM WHICH GENERATES DUE TO WATER}

Hankou experienced new urban construction period in modern times, and the urban area developed from Dragon King Temple to Danshuichi, from "along the river" to "along Yangtze River". The water is the source and lifeblood of Hankou's economy, the urban construction of Hankou in modern times was around the Yangtze River and Han River, which was a narrow and long area, also the earliest city model of Hankou.

In modern times, there were many wars in Wuhan, and the complicated wars changed the city appearance of Hankou, among which the most representative one was the port opening and establishment of concession in Hankou in 1861 and the construction of Hankou Tower in 1864. The establishment of concession in Hankou made Hankou leave the old city, and set large areas of Hankou along the river as concession, which was as large as the old city, and the architectural scale conformed to modern western cities. It also constructed avenues along the Yangtze River, several vertical and horizontal, parallel or perpendicular to the Yangtze River, and constructed municipal infrastructures like city road, tap water, water supply and sewerage, and street lamps. Later, the construction of Hankou Tower prevented the flood from eastern and western lakes and the back lake, preventing large areas of Hankou under the horizontal plane from suffering flood from the back lake, enlarging the area of Hankou by several times, and there were large areas in Hankou which offered construction site for modern city development.

The new city developing opportunity forms new architectural form due to the special conditions of three towns in Wuhan which connects rivers and there are many floods. The terrain of Hankou is low, the average elevation of which is $24 \mathrm{~m}$ (Wusong datumn level), and the flood in general years is around $2 \mathrm{~m}$ higher than the ground, and there are floods more or less in normal years.[6] There is one major flood every less than 20 years, in 1848, 1849, 1870, 1884 and 1931 in modern times, flood brought heavy blow to the construction of Hankou. Especially in 1931, it rained for successive 30-40 days in Wuhan area, raining and blowing hard along with heavy rainfall in the upstream of rivers, which led to abrupt rise of river and Han River. On 7.23, the water level of Jianghan reached $26.48 \mathrm{~m}$, Danshuichi dyke was broken, and hundreds of people died for it was too late to run away. On 8.19 , the water level of Jianghan reached $28.28 \mathrm{~m}$, creating the highest flood record during 70 years since Hankou hydrometric station was set up. On 8.29, Wuhan garrison headquarter published the disastrous situation: 321sq.kn of the three towns were drowned, and over 160,000 families and 780,000 people were affected, 230,000 people had no food and waited for relief, 13,000 people died "Fig. 1". [7] 


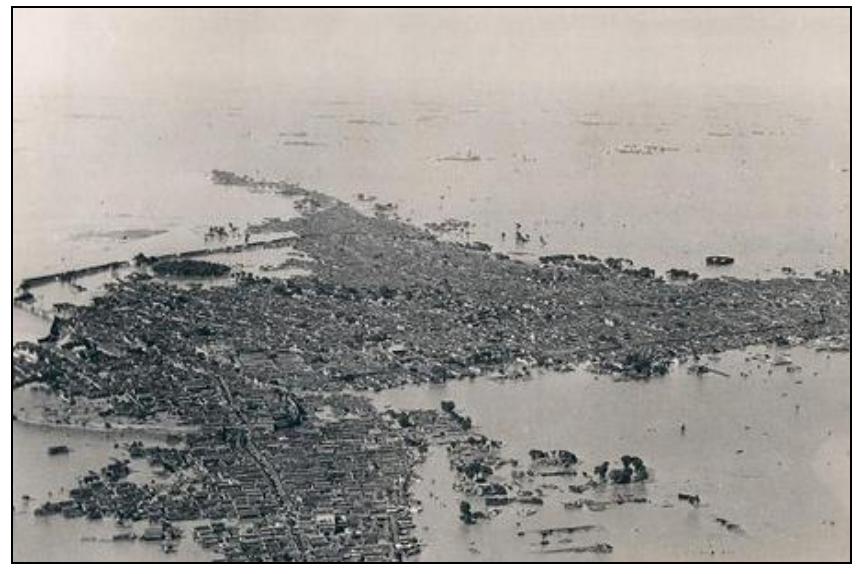

Fig. 1. The water in Hankou

Hankou is at the risk of flood all year around, and people there have gotten used to such life. The population of Hankou grew year by year. The architecture and water mutually reinforcing and neutralizing each other, those bad, unstable and underground buildings went up in smoke because they couldn't stand flood, what left were either temporary dwellings or classic buildings, the water is like wave sweeping away sand and forms magnificent building form like gold. The largescale construction of concession in Hankou added exoticism to the buildings of Wuhan, making the buildings be constructed based on full consideration of the region and climate of Hankou. The construction of avenue and wharf along the river becomes the most representative area of Hankou architecture in modern times, where there are large quantities of large buildings like consulates and banks.

The establishment of Hankou concession formed its development mode which kept pace with the old city. In first years, the volume of concession buildings was not large, merely 1 to 2 floors, not very different from local buildings, with only a few differences in architectural form and idea. These buildings which didn't adjust themselves to local conditions were soon beaten by water, and foreigners who could not stand flood had no choice but to redesign new architectural form to adapt the seasonal drowning in this area, and here arose high-bench buildings "Fig. 2". To prevent the buildings from being drowned during flood period, the main body had to be build above the flood level, and generally the building was lifted with one underground floor and several overground floors. The architectural features were mainly designed rationally from two aspects of form and function, and the perfect unification of indoor and outdoor produced a magnificent form. It mainly had following features:

- The datum plane of the building is over the horizontal plane, solving the problem of the main body being drowned. The ground floor is an empty space, and the datum plane is set on the second floor to control flood and humidity, also to serve as storeroom or garage.

- The entrance of the building is lifted to form high stairs, and people's visual horizon of the building is lifted, the sense of the building volume is enlarged, making the whole building seem lofty, straight and magnificent.
- The outer wall of the building mainly adopts stone material, which is solid and firm with exquisite construction technology, conforming to the eclecticism and romanticism of the whole building.

The permanent building constructed around 1920s generally adopted such high bench, such as HSBC building, BOC building, building of Bank of Communications, Yokohama Specie Bank building and Hankow Customs House.

In 1931 there was flood in Wuhan, making Hankou a watery area, and most of Wuchang and Hanyang was drowned, houses of which were immersed in water for over 2 months. However, these high-bench buildings were safe and sound, and the major floors could still serve normally. Buildings of Hankou Commercial Bank and the National Industrial Bank of China constructed after the flood also adopted such architectural form. Not only did it have the function of flood control, but also it improved the lofty sense of the building, making it an effective method normally adopted in buildings in modern times in Wuhan.

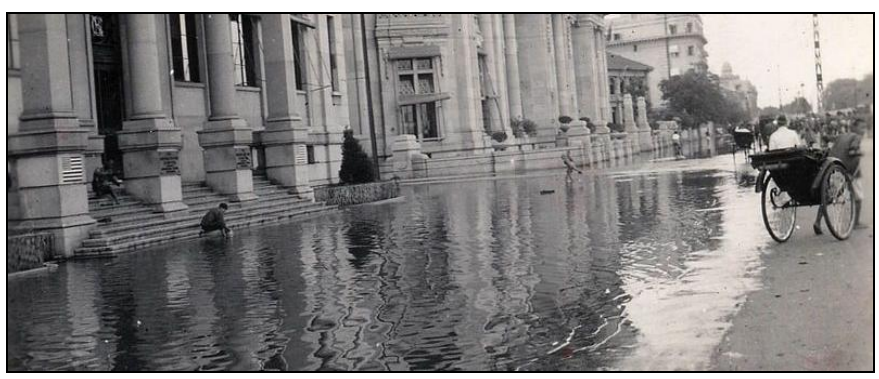

Fig. 2. Construction of high bench

\section{EXAMPLES OF MAGNIFICENT BUILDING IN HANKOU IN MODERN TIMES}

Yokohama Specie Bank (1907): located on No.129, Yanjiang Road, four-storeyed building in reinforced concrete structure with an area of 4969sq.m. It is a classical building with modern style, the granite pf the outer wall is up to the top, the corner serves as the main entrance, and on the two sides are empty colonnades, Ionic double columns, there is no complicated floriation on the outer wall, which is dignified and plain. There are 7 rooms of the side along Nanjing Road, and 5 rooms on the side along the river, and there is a gate with 15 outer stairs to enter the second floor on the both sides, the ground floor of the building serves as warehouse. The middle business hall on the second floor is $26 \mathrm{~m}$ long, $13 \mathrm{~m}$ wide with caisson on the top for lighting, which is up to the top of the third floor, and there is no column inside the hall. There is a business room on the two sides one front side of Yanjiang Road, the office building on the third floor connects to the overhanging corridor along the upper part of the business hall, and the fourth floor is for apartment. The entrance hallway at the corner of the building can lead to the business hall, and it also has stairs to lead to the third and fourth floors. The floor of the hallway and the stair surface up to the third floor are paved with white marble, and the ground of the business hall is paved with terrazzo, and office and apartment space all adopt wood floor. 
Hankow (Customs House 1924): the main body has 4 floors, $20 \mathrm{~m}$ high, the ground floor is the pendulum room, the second floor is the room for parts of the large bell, the third floor is the room for hour pointer of the bell, and the top floor is the sound room consisting of 7 scales. There are stairs leading to the top floor; the outer wall of the bell tower is inlaid with large clock dial with 3-meter diameter, and the pointer is $1.7 \mathrm{~m}$ long. There is wind indicator on the bell tower inlaid with a gilded British sailing boat. The style of the whole bell tower is special form of Britain, which is elegant and magnificent. It directly faces the Yangtze River, located on the intersection of Jianghan Road and Yanjiang Road, guarding the south of the old concession, and facing the whole concession and the river in the north and entrance of Han River in the south. This building was international advanced then no matter in appearance or construction quality, owning the good reputation of "Oriented Chicago".

When the building is being designed, the designer was very open on design idea, and didn't adopt single architectural form and style but gathered features of various architectural schools and integrated them all. The top is $83.8 \mathrm{~m}$ above the ground, which was the second highest vertical building then in Wuhan. In aspect of basic work, it changed former building foundation which took boulder strip as foundation and adopted reinforced concrete raft foundation. Ever since cement was introduced to Wuhan in 19th century, reinforced concrete was also introduced and replaced boulder strip gradually. The outer wall adopted granite, which was mostly produced in Hunan, with decorative design on it, solid and beautiful. There are granite aisle columns on the east, west and north sides of the building, decorated with distorted classical "Corinthian order". The diameter of these columns reached $1.5 \mathrm{~m}$, about $10 \mathrm{~m}$ high, and it needed two people to encircle one. There are middle corridors on from second to fourth floors, the hollow black bars connect granite aisle column, a combination of softness and hardness, crudeness and fineness, which could be said as extremely skillful, making people acclaim as the peak of perfection. When facing the 28 stairs toward the gate and the aisle columns, people could feel the dignity and elegance of the building. The building design adopted three-part composition, highlighting the middle entrance with the bell tower, expressing classicism; the wall, windowsill and entrance adopted arch, highlighting western Renaissance, which was the typical architectural style. For the back part of the building, there was a south opening, making the building present a three-section compound. The designer might considered the connection to the old city, and such design could keep in harmony with the neighborhood.

HSBC (1917): designed by Shanghai British architect Pinar, located on No.103, Yanjiang Road, Hankou, built in 1917. The construction was invested by HSBC headquarters, and Hanxiesheng Construction Factory built it. It covered an area of 3591sq.m, and it had 3 floors, about $20 \mathrm{~m}$ high. The total area was $10244 \mathrm{sqm}$, reinforced concrete structure. HSBC stressed symmetric axis, harmonious proportion and clear distinction, and it properly adjusted the normal proportion of " 3 horizontal and 5 vertical" of classicism, and changed into proportion of " 5 horizontal and 3 vertical" to fit the 1:4 depthwidth ratio of the main facade of the building. The granite of the outer wall was layered up to the top, and 10 Ionic Orders were connected by granite. To guarantee the harmony of the whole building, it lifted the entrance of the first floor, and there were 15 stairs in front of the aisle column, increasing the height of the foundation, improving the stability of the building while preventing flood. The front section of the building took tow business halls as the main subject, and the back section was office room, with four coffers in the middle, the layout of which was compact. There were 3 lifts and 3 staircases in the building. The indoor terrace paved wood floor on the reinforced concrete floor, there was wooden dado indoors, and the decoration was exquisite and elegant with fireplace and water and power utilities.

The facade of the building which faced the river was divided into 3 parts vertically and 5 parts horizontally, and a bulge in the middle was the main entrance, the facade was strictly symmetric in magnificent dimension, which was a typical building in classical style. There are 3 overground floors in the main building, with 4 overground floors and 3 underground floors of the wing building. There were 3 steelstructural colorful glass vault inlaid with flowers on the business hall on the first floor. On the ceiling was caisson. Ionic Order which imitated ancient Greece seemed long and beautiful, and there were exquisite decorative patterns on the column foundation and column top; there were exquisite reliefs on the window sill, outrigger, door and window lintel; all the floors indoors paved wood floor with reinforced concrete floor; it adopted wooden dado, and the middle corridor was inlaid with marble, the external corridor was paved with mosaic tiles; there were decorative components on beam and column; there was a colorful glass dome structure inlaid with flower in steel structure in the middle of the hall, adding colorful harmonious glare to the hall on the first floor, and the ceiling caisson, column decoration and dado in the hall set off the magnificence of the building.[8]

Wuhan is a mixed city, merchants always on the move and Hankou residents living there for generations all call themselves as Wuhan people, who don't oppose everything foreign and absorb anything and everything. Hankou-oriented magnificent modern architecture is the major representative of modern architecture of Wuhan, and tourists who visit Hankou will all go to the pedestrian street on Jianghan Road and Hankou bund to appreciate the beauty of high-bench architecture.

\section{REFERENCES}

[1] Wang Gang. Analysis on origin of Hankou architecture [J]. Huazhong Architecture, 2012. No. 12: 142-147

[2] Local chronicles office, Hanyang District, Wuhan. Journal of Hanyang during Kangxi's reign (1). Yudizhi [M]. Wuhan: Hubei People's Publishing House, 2014-11

[3] Liu Xianting. Guangyangzaji (4) [M]. Beijing: Zhonghua Book Company, 1957: 193

[4] http://blog.sina.com.cn/s/blog_474b683401000as6.html

[5] Li Chuanyi, Zhang Fuhe. Overview of modern Chinese architecture [M] Beijing: China Construction Industry Press, 1992.2: 13

[6] US. William Rowe. Hankou: conflict and community of a Chinese city [M]. Translated by Lu Xiqi, Luo Dufang. Beijing: China Renmin University Press, 2008.3:110-111 
[7] Compilation committee of local chronicles, Jiang'an District, Wuhan. Journal of Jiang'an District [M]. Wuhan: Wuhan Press, 2009.10:1190

[8] Pi Mingxiu. City history of modern Wuhan [M]. Wuhan: China Social Sciences Publishing House, 1993 